\title{
The Synergistic Relationship Between Climate Change and the HIV/ AIDS Epidemic: A Conceptual Framework
}

\author{
Mark Lieber $^{1}$ (i) $\cdot$ Peter Chin-Hong ${ }^{2} \cdot$ Henry J. Whittle ${ }^{3} \cdot$ Robert Hogg $^{4} \cdot$ Sheri D. Weiser ${ }^{5}$
}

Accepted: 31 December 2020 / Published online: 15 January 2021

(c) The Author(s), under exclusive licence to Springer Science+Business Media, LLC part of Springer Nature 2021

\begin{abstract}
Climate change and HIV/AIDS represent two of the greatest threats to human health in the 21st century. However, limitations in understanding the complex relationship between these syndemics continue to constrain advancements in the prevention and management of HIV/AIDS in the context of a rapidly changing climate. Here, we present a conceptual framework that identifies four pathways linking climate change with HIV/AIDS transmission and health outcomes: increased food insecurity, increased prevalence of other infectious diseases, increased human migration, and erosion of public health infrastructure. This framework is based on an in-depth literature review in PubMed and Google Scholar from June 6 to June 27, 2019. The pathways linking climate change with HIV transmission and health outcomes are complex with multiple interacting factors. Food insecurity emerged as a particularly important mediator by driving sexual risk-taking behaviours and migration, as well as by increasing susceptibility to infections that are common among people living with HIV (PLWHIV). Future interventions should focus on decreasing carbon dioxide emissions globally and increasing education and investment in adaptation strategies, particularly in those areas of sub-Saharan Africa and southeast Asia heavily impacted by both HIV and climate change. Environmentally sustainable interventions such as urban gardening and investing in sustainable agriculture technologies also have significant health co-benefits that may help PLWHIV adapt to the environmental consequences of climate change.
\end{abstract}

Mark Lieber

mark.lieber@gmail.com

1 Johns Hopkins Bayview Medical Center, 4940 Eastern

Avenue, Baltimore, MD 21224, USA

2 University of California, San Francisco (UCSF), School of Medicine, 513 Parnassus Avenue, San Francisco, CA 94143, USA

3 Queen Mary University of London, Centre for Psychiatry, Wolfson Institute of Preventive Medicine, Barts and the London School of Medicine and Dentistry, Charterhouse Square Campus, UK

4 BC Centre for Excellence in HIV/AIDS, Division of Epidemiology and Population Health, Vancouver, Canada

5 University of California, San Francisco (UCSF), Division of HIV, Infectious Disease and Global Medicine, San Francisco, CA 94143, USA 


\section{Graphic Abstract}

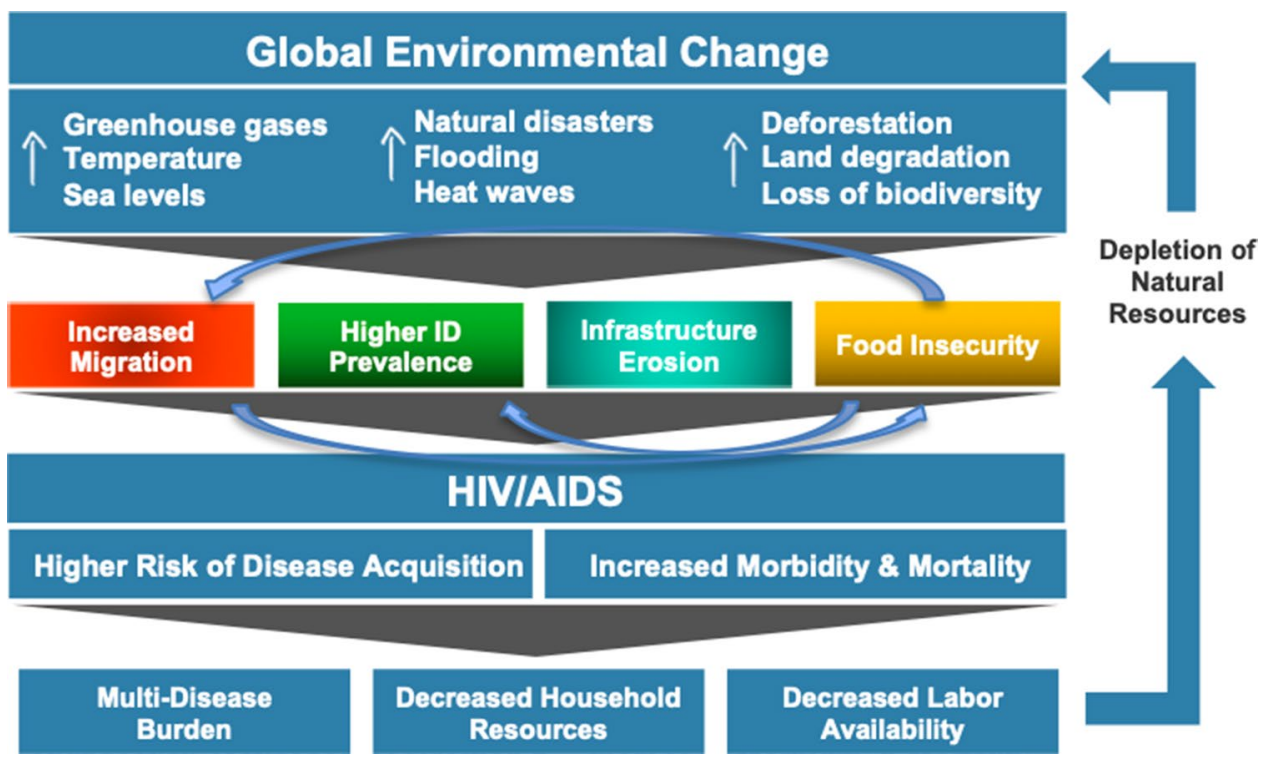

Keywords HIV $\cdot$ Climate change $\cdot$ Conceptual model $\cdot$ Food insecurity $\cdot$ Human migration

\section{Introduction}

The health challenges arising from climate change and the HIV/AIDS epidemic are unprecedented in human history. A ground-breaking study in 2020 forebodes that our planet could see a greater rise in temperatures in the next 50 years than it did in the last 6000 years as a consequence of human activities [1]. Without swift adoption of powerful mitigation and adaptation strategies, these temperature changes will drive extreme weather events such as droughts and floods, alter coastlines, and dramatically affect access to adequate food, clean water, and reliable shelter over the coming years [2-4]. According to the World Bank, these effects are projected to cause an additional 5 million deaths between 2030 and 2050 - mainly from malnutrition, malaria, and diarrheal diseases - and force over 100 million additional people into extreme poverty [5]. Meanwhile, to date, over 70 million people have been infected with the HIV virus worldwide, nearly half of whom have died. According to the World Health Organization, 38.0 million people were living with HIV in 2019 and 690,000 deaths were caused by HIV/AIDS [6]. Consequently, the global burden of HIV/AIDS remains one of the foremost challenges facing healthcare systems worldwide.

The overlap between climate change and HIV/AIDS is of paramount global public health importance, particularly since both disproportionately impact regions of global vulnerability such as sub-Saharan Africa (SSA) and Southeast Asia (SEA) that are heavily impacted by both HIV and climate change. In this context, "vulnerability" can be seen as having two components: the stresses that people are subjected to (external) and their capacity to cope with those stresses (internal) [7, 8]. This logic has already been used to explain the "new variant famine" hypothesis, whereby communities with a higher HIV prevalence are more heavily impacted by moderate flooding and droughts due to their relative inability to recover from these events [9].

Environmental justice has emerged as an important lens for assessing the disproportionate impact of climate change on vulnerable populations, including PLWHIV [10]. Environmental justice is a theoretical and activist framework that aims to expose inequities in the distribution of natural resources among disadvantaged and minority groups [11]. HIV/AIDS can be framed as an environmental justice issue due to the intimate connection that exists between natural resource allocation and the transmission and progression of HIV/AIDS. This is particularly true in the agrarian communities of SSA and SEA that rely heavily on subsistence farming for income and food security [12]. For example, the World Bank predicts that $1.5^{\circ}-2{ }^{\circ} \mathrm{C}$ of warming will result in a $40-80 \%$ reduction in food production in SSA due to droughts, flooding and shifts in rainfall [13]. This 
Fig. 1 Conceptual model linking climate change with HIV health outcomes

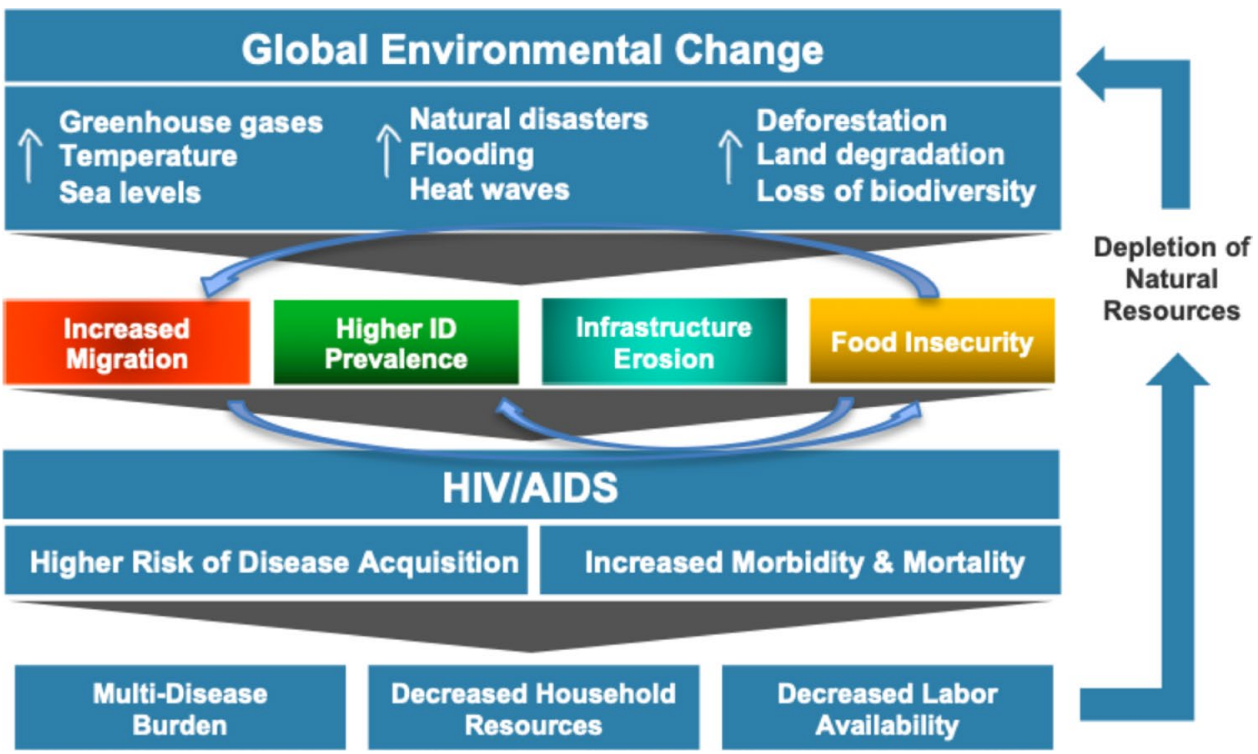

is especially important since over two thirds of all people living with HIV currently live in the WHO African Region (25.7 million) [6], with an additional 3.8 million living in SEA [14].

A few studies have highlighted the relationship between climate change and HIV morbidity and mortality. A 2019 study showed that drought conditions were significantly associated with riskier sex behaviors and higher HIV prevalence rates among rural females 15-19 years old living in Lesotho [15]. Another study of 19 countries in SSA in 2014 showed that HIV infection rates in HIV-endemic areas increased by approximately $11 \%$ for every recent drought [16]. However, there is limited literature to date identifying links between climate change and HIV health outcomes. Here, we present a conceptual model to better understand the potential pathways linking climate change with HIV incidence and health outcomes.

\section{Conceptual Model}

Four pathways linking climate change with HIV/AIDS are summarized in Fig. 1. This model is based on an in-depth literature review of the interaction between climate change, food insecurity, infectious diseases, human migration, destruction of healthcare infrastructure, and HIV/AIDS performed between June 6 and June 27, 2019. Specifically, this search occurred in three phases. The first phase looked at the literature linking climate change with HIV outcomes and included the search terms: [("climate change" OR "global warming") AND ("HIV" OR "human immunodeficiency virus" OR "AIDS")]. The second phase looked at the literature on climate change and the four proposed pathways using the search terms: [("climate change" OR "global warming")
AND ("food insecurity" OR "food access" OR "crop yields" OR "infectious diseases" OR "vector-borne diseases" OR "malaria" OR "fungal diseases" OR "diarrheal diseases" OR "human migration" OR "climate refugees" OR "health infrastructure")]. The third phase looked at the relationship between HIV and the four pathways using the search terms: [("HIV" OR "human immunodeficiency virus" OR "AIDS") AND ("food insecurity" OR "food access" OR "crop yields" OR "infectious diseases" OR "vector-borne diseases OR "malaria” OR "fungal diseases" OR "diarrheal diseases" OR "human migration" OR "health infrastructure")]. A preliminary search in PubMed and Google Scholar was restricted to English-language articles published after 2000, and a subsequent search of references from the relevant literature led to the inclusion of a handful of novel studies and reports from the 1990s. A review of the literature linking climate change, HIV and COVID-19 was also conducted in Google Scholar on September 12, 2020.

The conceptual framework proposes that various dimensions of global climate change-including increases in temperature, sea levels, greenhouse gas levels, and extreme weather events-impact the HIV/AIDS epidemic via four pathways: increased food insecurity, increased prevalence of other infectious diseases that negatively impact HIV/AIDS outcomes, increased human migration (or "climate refugees"), and erosion of public health infrastructure including HIV prevention and treatment services.

We propose that these four pathways impact the global HIV/AIDS burden by increasing transmission of the HIV virus and by worsening health outcomes among those already infected. For example, food insecurity related to climate change is known to increase HIV transmission by fuelling substance use, heightening gender disparities, and 
driving sexual risk behaviours (including sexual violence against women and transactional "food-for-sex") [17-19]. Simultaneously, food insecurity worsens health outcomes among people living with HIV by degrading immune function and compromising adherence to, and efficacy of, antiretroviral therapy (ART) [20-23]. Food insecurity is an especially important mechanism as it feeds into some of the other pathways such as increased migration and prevalence of other infections.

Changes in the distribution of certain infectious diseases due to climate change-particularly malaria and diarrheal diseases-will also increase the vulnerability of certain populations to acquisition of HIV and decrease health outcomes for those already living with the virus [24, 25]. Specifically, those with untreated HIV are more likely to have serious outcomes from secondary infections and are more likely to spread the virus due to increases in HIV viral load from immune activation $[26,27]$.

Climate-induced human migration from flooding, droughts, and extreme weather events also increases HIV transmission and decreases outcomes for those already living with the virus. For example, human migration results in the enlargement and extension of new sexual networks, which also creates conditions conducive to substance abuse. At the same time, human migration worsens health outcomes among those with the virus by disrupting access to HIV care and ART [28-30].

Finally, destruction of health and transportation infrastructure due to floods and extreme weather events affects access to HIV prevention and treatment services. This increases transmission of HIV due to decreased access to condoms and other prevention services and worsens health outcomes among those already infected through interruptions in ART access and treatment [31, 32].

It should be emphasized that many of these pathways are also bi-directional, with the HIV/AIDS epidemic having secondary environmental consequences due to depletion of natural resources and workforce shortages. For example, decreased labour availability due to HIV/AIDS can lead to a reduction in farm upkeep, further exacerbating land degradation caused by extreme weather events and unpredictable climate patterns $[9,33]$.

\section{Food Insecurity}

According to the United Nations' Food and Agricultural Organization, food security can be defined as: (i) the availability of sufficient quantities of food of appropriate quality; (ii) access by individuals to adequate resources for acquiring foods for a nutritious diet; (iii) utilization of food through adequate diet, clean water, sanitation, and health care to reach a state of nutritional well-being where all physiological needs are met; and (iv) stability, because to be food secure, a population, household or individual must have access to adequate food at all times [4].

Food insecurity is inextricably linked to climate change due to the direct relationship that exists between crop production and climatic factors such as temperature and precipitation [4, 34]. Climate change impacts crop production, and therefore food availability, through a number of different pathways including the negative effects of rising temperatures on soil moisture; higher ozone levels directly damaging crops; the destruction of crops by floods, drought, or other extreme weather events; and reduced crop yields due to inconsistencies between predicted and actual seasonal rainfall $[4,35,36]$. However, food availability is not the only dimension of food security that is impacted by a changing climate. Food access is also restricted due to changes in food pricing, destruction of roads, and damage to shops and other basic infrastructure [4]; stability is impacted by increased variability in the food supply as well as increased migration and civil unrest [37, 38]; and utilization is impacted by disparities in food allocation and a reliance on drought and flood-resilient crops such as cassava that are devoid of important micronutrients [39].

The effects of climate change on crop production differ substantially in different global regions [4]. However, under nearly all climate change projections, crop yields are projected to decrease in the tropical, or lower latitude, regions such as SSA, SEA, and much of Latin America - the areas most dependent on subsistence agriculture for food and income [12]. In southern Africa, for example, total precipitation is predicted to decrease by $15-45 \%$ by the end of the century [40]. Without adaptation to these changes, resulting droughts, flooding, and reduced crop production are projected to result in approximately 10 million more malnourished children in the region by 2050 [41]. The story is similar in Southeast Asia, where crop yields are projected to drop $17.3 \%$ by 2080 due to climate change, threatening the stability of both local and national economies in the region [42].

The relationship between food insecurity and HIV is also complex. Food insecurity drives transactional sex for money or food and heightens the risk of condom-less sex and gender-based violence by aggravating women's disempowerment, thereby increasing HIV transmission [17-19, 43]. Food insecurity also creates conditions conducive to substance use and poor mental health by driving rural-tourban migration and disrupting social networks, which then increase the risk of horizontal viral transmission [44, 45]. Malnutrition and risky infant-feeding practices among foodinsecure mothers also elevates the risk of vertical mother-tochild transmission [46].

Among PLWHIV, food insecurity negatively impacts individuals along the entire cascade of care. Specifically, 
food insecurity has consistently been shown to compromise ART adherence and also prompts PLWHIV to miss scheduled clinic visits $[47,48]$. A number of mechanisms underlie these associations, including resource trade-offs between money to buy food, medicines, and transport to clinics; worsened side effects when taking ART without food; and poor mental health driven by food insecurity [49, 50]. Depressive symptoms may also detrimentally impact HIV outcomes independent of ART [51]. As a result of these associations, food insecurity has been consistently associated with incomplete viral suppression and increased HIVrelated morbidity and mortality $[52,53]$. Furthermore, consequences of food insecurity such as weight loss, low BMI (in $\mathrm{kg} / \mathrm{m}^{2}$ ), low albumin, and micronutrient deficiencies have all been shown to predict opportunistic infections, immunologic decline, and shorter survival time in both untreated and ART-treated individuals [54-58]. Finally, lack of food may impede optimal absorption of certain antiretroviral medications, which may, in turn, contribute to treatment failure [59].

\section{Infectious Diseases}

In 1993, The Lancet published a prominent series linking climactic changes such as longer seasons, hotter temperatures, and alterations in rainfall patterns with changes in infectious disease prevalence and distribution. Since then, hundreds of studies have explored the relationship between climate change and infectious diseases. Climate change is predicted to alter the prevalence and distribution of numerous infectious diseases, including vector-borne diseases such as malaria, dengue, and Lyme disease, as well as various water-borne diseases and fungi [60-65]. Those who are immunocompromised, including those with untreated HIV infection, are more prone to developing serious infections with many of these diseases [66-68]. HIV-infected individuals who have concurrent co-infections with malaria and other insect borne or water borne infections are also known to have worse HIV health outcomes [69, 70].

\section{Vector-Borne and Zoonotic Diseases}

By 2100 , average global temperatures are expected to rise 1.0-3.5 degrees Celsius, increasing the distribution of disease vectors such as mosquitos and ticks to areas that are currently too cold for them, particularly in higher altitudes [71-73]. Distribution of the Anopheles mosquito that carries malaria, for example, is projected to move into the highlands of Ethiopia, Kenya, Zimbabwe, and South Africa, where HIV prevalence is among the highest in the world [74]. While important human variables such as poverty, healthcare access, and mosquito control efforts may alter predictions significantly, current estimates suggest that malaria will increase by five percent by 2030 due to climate change, mostly among populations in SSA that already have a high prevalence of HIV [60].

Vector-borne diseases such as malaria provide a formidable immunological challenge to those with HIV, whose immunocompromised state makes them more vulnerable to serious infections and death. An interaction between malaria and HIV infection was first noted in multigravida pregnant women in the 1980s, when Steketee and others found that HIV infection impaired these pregnant women's ability to control malarial parasitemia [69]. Since then, multiple studies have shown a clinical interaction between malaria and HIV-1 infections, with one suggesting that nearly $30 \%$ of the HIV disease burden comes from malaria co-infections [27, $67,75]$. In addition to HIV increasing one's susceptibility to the malaria parasite, co-infection with malaria also appears to increase HIV viral loads among those who are dually infected, [67] likely due to immune activation. In Malawi, for example, studies have shown nearly a doubling of HIV viral load in subjects following malarial infection, confirming earlier reports from both Malawi and Uganda showing an acute rise in HIV viral load at the time of malaria infection [24].

While mosquitoes are the disease vectors most frequently studied in connection to climate change [76, 77], climate change is also expected to alter the distribution of other vectors such as ticks and sandflies, driving other HIV-associated diseases such as leishmaniasis [72]. Climate change can affect the distribution of leishmaniasis both directly, through the positive effects of temperature on parasite development in the sandfly guts, and indirectly, through changes in the range of sandfly species [78]. In Brazil, for example, changes in temperature and precipitation due to the El Niño cycle have been positively associated with the annual incidence of leishmaniasis in the region [79]. Coinfection with HIV and leischmaniasis is also known to worsen both infections, with treatment failure of leischmaniasis high among those with HIV and HIV replication and progression to AIDS common during leischmaniasis infection [80].

Finally, there is already substantial literature implicating climate change as a factor in the emergence and spread of COVID-19, a zoonotic respiratory virus. Climate change is already known to affect the distribution of zoonotic diseases by altering the geographic range and population density of animal vectors such as bats and rodents, resulting in dramatic increases or decreases in host reservoirs of disease [81]. Climate change has also been implicated in the spread of the COVID-19 due to increased human population density, human migration, urbanization, and frequency of human-wildlife interactions [82-85]. While COVID-19 may contribute to worse outcomes among immunocompromised populations, thus far PLWHIV with well-controlled disease 
do not appear to be at risk of poorer COVID-19 health outcomes compared to the general population [86]. Yet, the COVID-19 pandemic has negatively affected antiretroviral adherence in many countries due to lockdown measures [87]. In China, for instance, $48.6 \%$ of PLWHIV reported difficulties accessing their HIV antiretroviral medication due to COVID-associated lockdowns [88].

\section{Water-Borne Diseases}

Some water-borne diseases are also expected to increase due to human-induced climate change, with more than 130,000 additional cases of diarrheal disease per year expected by 2030 due to flooding and extreme weather events [60]. A recent study in a region of Botswana with a high HIV prevalence, for example, found that climate-associated extremes of rainfall, temperature, and river height were significantly associated with both river $E$. coli concentrations and clinical cases of paediatric diarrhoea reported in local hospitals [89]. Other common diarrhea-causing organisms that may increase in prevalence due to climate change include Entamoeba histolytica, Vibrio cholera, Giardia lamblia, and soil-transmitted helminths [60, 90, 91]. For those infected with a diarrhea-causing organism, co-infection with HIV is associated with significant morbidity and mortality, particularly where financial and human resources are limited. In such cases, rapid and severe dehydration can lead to further deterioration of the immune system, acute renal failure, and increased susceptibility to septicaemia [92, 93].

One particularly devastating water-borne disease associated with climate change is cholera. Outbreaks of cholera have been associated with zooplankton blooms, warmer water, and severe storms, all of which are likely to increase with climate change [91, 94]. In South America (Peru) and Bangladesh for example, warming water temperatures associated with El Niño events have already been shown to trigger the resurgence of cholera [95]. A number of studies have also supported a link between cholera and HIV [96, 97], with one case-control study in Mozambique showing that HIVinfected individuals were 2 to 3 times more likely to acquire cholera than controls who were not HIV-infected [70].

\section{Fungal Diseases}

Finally, many important HIV-associated opportunistic infections are fungal infections, including pneumocystis, cryptococcosis, coccidiomycosis, and histoplasmosis [98]. Outbreaks of these fungi are strongly linked with climate metrics such as decreased precipitation and increased temperature due to the ability of fungal spores to travel long distances in dust, dirt, and dried bird droppings [99]. In the United States, for example, drought conditions in the southwest have frequently been linked with coccidiomycosis outbreaks [100]. Immunocompromised individuals, including those with untreated HIV infections, are also more prone to develop serious, even life-threatening, fungal infections [101]. During a three-year period of drought in Arizona from 1990 to 1993 , for example, $10 \%$ of HIV-infected patients hospitalized in the state had a diagnosis of coccidiomycosis infection, one-third of whom died from the infection [102].

\section{Human Migration}

In the context of climate change, human migration is often seen as a last-resort option following multiple adaptations to climate-related stress [103]. A model proposed by Biermann and Boas suggests that climate migrants, or refugees, are "people who have to leave their habitats, immediately or in the near future, because of sudden or gradual impacts of climate change." This migration may be temporary or permanent, depending on a number of factors including the adaptive capacity of the affected community and persistence of the environmental insult [104].

Climate change is projected to increase human migration in the coming decades due to a combination of factors including rising sea levels, extreme weather events, conflicts over depleting natural resources, and food insecurity [2, 105]. According to the IPCC, sea levels are likely to rise by about half a meter by the year 2095 because of melting glaciers [106], threatening over 600 million people worldwide who live in low-elevation coastal areas [107]. In Bangladesh, for example, rural to urban migration has skyrocketed over the past twenty years due to increased flooding in rural regions. One report suggests that $22 \%$ of households affected by tidal-surge floods and $16 \%$ of those affected by riverbank erosion in rural areas of Bangladesh have migrated to urban areas, resulting in over 500,000 internal migrants and 3 million international migrants every year [109]. However, the strongest impacts of climate change on human migration will be seen in sub-Saharan Africa, which is projected to see 86 million climate change migrants by 2050 due to decreased crop productivity and water shortages [108]. In South and Southeast Asia, unpredictable rainfall and drought have also resulted in the migration of more than eight million people to the Middle East, Europe and North America, with an additional 40 million internal migrants predicted by 2050 [108]. Worldwide, a combination of droughts, floods, and rising sea levels are projected to result in the migration of anywhere from 200 million to 1 billion people by the year 2050 [110, 111].

The link between human migration and the spread of HIV has been well-known since the beginning of the AIDS epidemic. Human migration patterns have frequently been used to explain the variation in HIV throughout SSA as well as the spread of the virus from west Africa to east and southern 
Africa in the 1980s and 1990s [92, 93]. One study suggests that human migration can account for $57 \%$ of the variation in HIV prevalence among women and $24 \%$ of the variation among men across SSA between 1985 and 1994 [28, 112, 113].

Migration drives HIV transmission and poor HIV outcomes through a number of different pathways including: increased sexual networks, sexual exploitation due to food insecurity, increased drug use, urbanization, reduced accessibility to prevention and treatment services, and reduced adherence to antiretroviral medications [7, 28]. The expansion of sexual networks is a particularly important mechanism. Many studies suggest that migrants-particularly seasonal or temporary migrants-are more likely to have expanded sexual networks and engage in riskier sexual behaviours than non-migrants [112, 114, 115]. For example, studies along the borders of South Africa, Mozambique, and Zimbabwe-a region with the highest HIV rate in the world-have consistently shown high rates of economic and sexual exploitation among migrants [38].

Urban migration is also projected to accelerate rapidly in the coming decades as a response to climate change. Worldwide populations are projected to increase from 7.7 billion today to over 10 billion by 2100 , with the majority of growth occurring in urban areas [116]. In 2050, for example, nearly $70 \%$ of the world's population is projected to live in cities, up from 55\% in 2018 [117, 118]. Urbanization is a key factor mediating the relationship between human migration and HIV/AIDS, particularly since urbanization is occurring faster in SSA than any other part of the world $[28,38]$. According to one report, more than $50 \%$ of the population of SSA is projected to live in urban areas by 2030 , up from $40 \%$ in 2020 [119, 120]. This is particularly concerning because HIV rates are higher in every major city in SSA (with the exception of Cape Town) than the corresponding national HIV prevalence rates [38]. Without a vaccine, there will therefore be a continual pool of young men and women, especially in Africa, who are at increased risk of HIV and other sexually transmissible diseases.

\section{Erosion of Health Systems}

Finally, increases in natural disasters and extreme weather events will likely erode existing public health infrastructure, particularly in the poorest areas of the world where such infrastructures are already strained due to a lack of finances, transportation systems, and trained workers [32]. Flooding and severe storms, in particular, destroy clinics, hospitals, and transportation networks that are vital to the functioning of public health systems [121]. They can also divert resources away from the healthcare sector in order to address other emergency priorities such as shelter and food
[122]. Without strong public health infrastructure, it is difficult, if not impossible, to effectively provide HIV prevention or treatment services to communities impacted by extreme weather events. For example, extensive flooding in Namibia in 2009 resulted in significant damage to at least 30 government health facilities and closure of an additional 41 health facilities and 179 outreach points due to inaccessible roads. Approximately $87 \%$ of the people living with HIV in the region reported a disruption in educational services due to the floods and $23 \%$ reported that they missed their medication due to the floods [123].

But even when clinics remain intact, destruction of roads during floods and other extreme weather events can decrease access to healthcare facilities for those who rely on antiretroviral medications to manage their HIV infection. In a novel 2011 study, Chinowsky et al. documented the potential cost impacts of climate change on road infrastructure in ten countries that are geographically and economically diverse. The researchers found that the opportunity cost of climate change on road construction was most pronounced in the countries of Bolivia, Ethiopia, Cameroon, and the Philippines due to a higher proportion of unpaved roads in these countries [124]. Other authors have continued to build on this methodology to help determine the potential impacts of climate change on bridges and roads in northern climates [125, 126].

In sub-Saharan Africa, the destructive impact of climate change on transportation infrastructure will be particularly pronounced. The African Development Bank has already called for $\$ 40$ billion USD per year over the coming decades to address development issues directly related to climate change in Africa [127]. It is estimated that three southern African countries-Malawi, Mozambique, and Zambiawill need to invest over $\$ 550$ million by 2050 to maintain and repair roads as a result of damages directly related to temperature and precipitation changes from climate change [128]. But we do not need to look to 2050 to see the destructive impact of climate change on roads in Africa. In 2007, flooding in Mozambique, Zambia, Zimbabwe, and Malawi downed bridges and washed away roads in all four countries. The floods - thought to be caused by erratic rainfall patterns due to climate change-hit southern Zambia particularly hard, preventing some 75,000 individuals from accessing a healthcare facility for nearly two months. Of these, approximately $16 \%$ were HIV-positive individuals who relied on antiretroviral therapy to manage the disease [31].

\section{Discussion}

Two of the greatest threats to human health in the 21st century—climate change and HIV/AIDS—are linked through a number of social, economic, and biological factors. In this paper, we have proposed a conceptual model demonstrating 
four pathways linking climate change and HIV: food insecurity, the spread of certain infectious diseases, human migration, and erosion of transportation and healthcare infrastructure.

Of these, food insecurity appears to be a particularly important mechanism that feeds into some of the other pathways such as increased migration and prevalence of other infections. Food insecurity is known to increase HIV transmission by fuelling substance use and decrease health outcomes among those already infected with HIV due to immune degradation. Policies that protect communities against food insecurity through long-term crop rotations and improved water conservation and storage measures, particularly in regions heavily impacted by HIV/AIDS, should therefore be prioritized in global policy agendas in the years ahead.

We propose several strategies aimed at weakening the effects of climate change on HIV health outcomes. First, mitigation strategies that reduce greenhouse gas emissions worldwide are key to slowing the acceleration of climate change. Ironically, those populations most affected by the interaction between climate change and HIV - those living in the resource poor regions of SSA and SEA-have also contributed the least in terms of production of carbon dioxide and other greenhouse gases. Rather, nations such as the United States, China, Russia, India, and Japan have led the world in carbon emissions and therefore bear much of the responsibility to reduce carbon emissions through mitigation efforts, in particular by investing in clean energy sources such as wind, solar, and hydroelectric power [129].

In the developing world, incentivizing collaborations between the public and private sectors to help cut carbon emissions should also be a core component of future mitigation efforts. Such technological "leapfrogging" has already been proposed to reduce greenhouse gas emissions and promote economic development in SSA [130]. Chinese companies like Suntech Power have already been effective in developing green technology in SSA and could help stimulate further international investment in the region [131]. The infusion of human and technological capital to support such a green "revolution" would also have many direct and indirect benefits to the local population and could prove to be a powerful message to the climate change and HIV communities worldwide [132]. Such efforts are also consistent with the goals of the environmental justice movement by incorporating historically disadvantaged groups in environmental policymaking and policy implementation [11].

Adaptation strategies that aim to the reduce the negative health impacts of climate change on vulnerable communities is also of paramount importance. In agrarian communities highly affected by climate change, adaptation strategies should include education and investment in sustainable technologies such as solar water pumps for year-round irrigation and agroforestry techniques for increased biodiversity and reduced erosion [133]. They should also focus on addressing climate-related HIV coinfections such as malaria by educating communities about the interaction with HIV and by distributing bed nets and draining sources of stagnant water $[134,135]$. At the national level, improving communication and collaboration between government ministries responsible for agriculture, health, and transportation should also be central to adaptation efforts to maximize resource utilization and increase overall program effectiveness. International partnerships that cross disciplinary boundaries and target the core issue of social vulnerability in these regions provide particular promise, including the Southern Africa Vulnerability Initiative (SAV) and the Regional Network on AIDS, Livelihoods and Food Security (RENEWAL) [136].

In the large cities of sub-Saharan Africa, increased seasonal or permanent migration from HIV-endemic areas also threatens to spread HIV from endemic populations to HIV naïve populations. Consequently, increasing the availability of evidenced-based HIV-prevention strategies such as preexposure prophylaxis and access to antiretroviral therapy for HIV-positive individuals will be crucial to limiting the spread of HIV in these communities. Including migrant health in city planning and establishing better surveillance systems to understand their risk factors and health outcomes will also aid in addressing the specific HIV-related health needs of migrants.

Finally, much more research and funding are needed to further elucidate the pathways linking climate change with HIV. For example, very little is known about the effects of climate change associated droughts and floods on healthcare infrastructure and healthcare delivery, particularly in rural areas. Longitudinal studies are needed to unpack associations between different extreme weather events and HIV indicators, and the factors that may enhance vulnerability to the negative health impacts from climate change such as race, poverty, and age. In addition, future studies should aim to be more regionally and geographically specific as climate change will alter temperature and precipitation patterns differently at different altitudes and latitudes. Lastly, there is a strong need for well-designed intervention studies to help assess specific climate adaptation or mitigation strategies that could be adopted by public and private entities worldwide to help mitigate the effects of climate change on those living with HIV.

\section{Conclusion}

Climate change and HIV/AIDS represent two of the greatest threats to human health in the 21 st century. Our conceptual framework presented here identifies four pathways linking climate change with HIV/AIDS transmission and health outcomes including increased food insecurity, increased 
prevalence of other infectious diseases, increased human migration, and erosion of public health and transportation infrastructure. Of these, food insecurity is a particularly strong mediator due to its contributing role in human migration and susceptibility to HIV co-infections. In order to lessen the effects of climate change on HIV transmission and outcomes, future interventions should focus on decreasing carbon dioxide emissions globally and increasing education and investment in adaptation strategies, particularly in those areas of sub-Saharan Africa and southeast Asia heavily impacted by both HIV and climate change.

Acknowledgements The authors would like to thank the Committee on Sustainability at the University of California, San Francisco (UCSF).

\section{Compliance with Ethical Standards}

Confict of interest All authors declare no conflicts of interest related to this manuscript.

\section{References}

1. Xu C, Kohler TA, Lenton TM, Svenning J-C, Scheffer M. Future of the human climate niche. Proc Natl Acad Sci. 2020;117(21):11350-5. https://doi.org/10.1073/pnas.19101 14117.

2. Warner K, Hamza M, Oliver-Smith A, Renaud F, Julca A. Climate change, environmental degradation and migration. Nat Hazards. 2010;55(3):689-715.

3. Parry ML, Rosenzweig C, Iglesias A, Livermore M, Fischer G. Effects of climate change on global food production under SRES emissions and socio-economic scenarios. Global Environ Change. 2004;14(1):53-67.

4. Wheeler T, von Braun J. Climate change impacts on global food security. Science. 2013;61453:508-13.

5. Hallegatte S, et al. Shock Waves: Managing the Impacts of Climate Change on Poverty. World Bank: Climate Change and Development; 2016.

6. WHO. HIV/AIDS, https://www.who.int/news-room/fact-sheets/ detail/hiv-aids. WHO (2020). Accessed 5 Sep 2020.

7. Talman A, Bolton S, Walson JL. Interactions between HIV/ AIDS and the environment: toward a syndemic framework. Am J Public Health. 2013;103(2):253-61. https://doi.org/10.2105/ ajph.2012.300924.

8. Drimie S, Casale M. Multiple stressors in Southern Africa: The link between HIV/AIDS, food insecurity, poverty and children's vulnerability now and in the future. AIDS Care-Psychol SocioMed Aspects AIDS/HIV. 2009;21(SUPPL. 1):28-33. https://doi. org/10.1080/09540120902942931.

9. de Waal A, Whiteside A. New variant famine: AIDS and food crisis in southern Africa. Lancet. 2003;362(9391):1234-7. https ://doi.org/10.1016/s0140-6736(03)14548-5.

10. Schlosberg D, Collins LB. From environmental to climate justice: climate change and the discourse of environmental justice. Wiley Interdisc Rev: Clim Change. 2014;5(3):359-74.

11. Lewis $\mathrm{N}$. An issue of environmental justice: Understanding the relationship among HIV/AIDS infection in women, water distribution, and global investment in rural sub-Saharan Africa. Black Women, Gender \& Families. 2009;3(1):39-64.
12. Janssens C, Havlík P, Krisztin T, et al. Global hunger and climate change adaptation through international trade. Nat Clim Change. 2020:1-7.

13. WB. What Climate Change Means for Africa, Asia, and the Coastal Poor. https://www.worldbank.org/en/news/featu re/2013/06/19/what-climate-change-means-africa-asia-coastalpoor. Accessed 5 Sep 2020.

14. WHO. HIV/AIDS in the South-East Asia, https://www.who.int/ southeastasia/health-topics/hiv-aids (2020). Accessed 5 Sep 2020

15. Low AJ, Frederix K, McCracken S, et al. Association between severe drought and HIV prevention and care behaviors in Lesotho: A population-based survey 2016-2017. PLoS Med. 2019;16(1):e1002727.

16. Burke M, Gong E, Jones K. Income shocks and HIV in Africa. Econ J. 2014;125(585):1157-89.

17. McCoy SI, Ralph LJ, Njau PF, Msolla MM, Padian NS. Food insecurity, socioeconomic status, and HIV-related risk behavior among women in farming households in Tanzania. AIDS Behav. 2014;18(7):1224-36. https://doi.org/10.1007/s 1046 1-013-0629-3.

18. Shannon K, Kerr T, Milloy MJ, et al. Severe food insecurity is associated with elevated unprotected sex among HIV-seropositive injection drug users independent of HAART use. AIDS. 2011;25(16):2037-42. https://doi.org/10.1097/QAD.0b013e3283 $4 \mathrm{~b} 35 \mathrm{c} 9$.

19. Oyefara JL. Food insecurity, HIV/AIDS pandemic and sexual behaviour of female commercial sex workers in Lagos metropolis, Nigeria. SAHARA-J: J Soc Aspects HIV/AIDS. 2007;4(2):626-35.

20. Weiser SD, Leiter K, Bangsberg DR, et al. Food insufficiency is associated with high-risk sexual behavior among women in Botswana and Swaziland. PLoS Med. 2007;10:1589-97. discussion 1598.

21. Oyefara JL. Food insecurity, HIV/AIDS pandemic and sexual behaviour of female commercial sex workers in Lagos metropolis Nigeria. SAHARA J. 2007;4(2):626-35.

22. Koethe JR, Heimburger DC. Nutritional aspects of HIVassociated wasting in sub-Saharan Africa. Am J Clin Nutr. 2010;91(4):1138S-1142S

23. Weiser SD, Gupta R, Tsai AC, et al. Changes in food insecurity, nutritional status, and physical health status after antiretroviral therapy initiation in rural Uganda. J Acquir Immune Defic Syndr. 2012;61(2):179-86. https://doi.org/10.1097/QAI.0b013e3182 $61 \mathrm{f064.}$

24. Kublin JG, Patnaik P, Jere CS, et al. Effect of Plasmodium falciparum malaria on concentration of HIV-1-RNA in the blood of adults in rural Malawi: a prospective cohort study. The Lancet. 2005;365(9455):233-40.

25. Githinji V, Crane TA. Compound Vulnerabilities: The Intersection of Climate Variability and HIV/AIDS in Northwestern Tanzania. Article. Weather Clim Soc. 2014;6(1):9-21. https://doi. org/10.1175/wcas-d-12-00052.1.

26. Wasserman P, Segal-Maurer S, Wehbeh W, Rubin DS. Wasting disease, chronic immune activation, and inflammation in the hivinfected patient. Topics Clin Nutr. 2011;26(1):14-28. https://doi. org/10.1097/TIN.0b013e318209e3a0.

27. Hewitt K, Steketee R, Mwapasa V, Whitworth J, French N. Interactions between HIV and malaria in non-pregnant adults: evidence and implications. Aids. 2006;20(16):1993-2004.

28. Voeten HA, Vissers DC, Gregson S, et al. Strong association between in-migration and HIV prevalence in urban sub-Saharan Africa. Sex Transm Dis. 2010;37(4):240.

29. Ngigi MM. A Geographical study on the HIV/AIDS pandemic in Kenya. Unpublished doctoral dissertation in Geoenvironmental Sciences submitted to the Graduate School of Life and Environmental Sciences, the University of Tsukuba. 2007. 
30. Tanser F, Bärnighausen T, Vandormael A, Dobra A. HIV treatment cascade in migrants and mobile populations. Curr Opin HIV AIDS. 2015;10(6):430-8. https://doi.org/10.1097/ coh.0000000000000192.

31. Schatz JJ. Floods hamper health-care delivery in southern Africa. Lancet. 2008;371(9615):799-800.

32. Tuller DM, Bangsberg DR, Senkungu J, Ware NC, Emenyonu N, Weiser SD. Transportation costs impede sustained adherence and access to HAART in a clinic population in southwestern Uganda: a qualitative study. AIDS Behav. 2010;14(4):778-84.

33. Parker DC, Jacobsen KH, Komwa MK. A qualitative study of the impact of HIV/AIDS on agricultural households in Southeastern Uganda. Int J Environ Res Public Health. 2009;6(8):2113-38. https://doi.org/10.3390/ijerph6082113.

34. Dawson TP, Perryman AH, Osborne TM. Modelling impacts of climate change on global food security. Clim Change. 2016;134(3):429-40. https://doi.org/10.1007/s1058 4-014-1277-y.

35. Jha UC, Bohra A, Singh NP. Heat stress in crop plants: its nature, impacts and integrated breeding strategies to improve heat tolerance. Review. Plant Breed. 2014;133(6):679-701. https://doi. org/10.1111/pbr.12217.

36. Hagos S, Lunde T, Mariam DH, Woldehanna T, Lindtjorn B. Climate change, crop production and child under nutrition in Ethiopia; a longitudinal panel study Article. Bmc Public Health. 2014;14(9):884. https://doi.org/10.1186/1471-2458-14-884.

37. McGregor J. Climate change and Involuntary migration: implications for food security. Food Policy. 1994;19(2):120-32.

38. Crush J, Grant M, Frayne B. Linking migration. Citeseer: HIV/ AIDS and urban food security in Southern and Eastern Africa; 2007.

39. Schmidhuber J, Tubiello FN. Global food security under climate change. Proc Natl Acad Sci. 2007;104(50):19703-8.

40. Serdeczny O, Adams S, Baarsch F, et al. Climate change impacts in Sub-Saharan Africa: from physical changes to their social repercussions. Reg Environ Change. 2017;17(6):1585-600.

41. Nelson GC, Rosegrant MW, Koo J, et al. Climate change: Impact on agriculture and costs of adaptation. Intl Food Policy Res Inst. 2009;21

42. Zhai F, Zhuang J. Agricultural impact of climate change: A general equilibrium analysis with special reference to Southeast Asia. Climate change in Asia and the Pacific: How can countries adapt. 2012;17-35.

43. Camlin CS, Kwena ZA, Dworkin SL, Cohen CR, Bukusi EA. She mixes her business: HIV transmission and acquisition risks among female migrants in western Kenya. Soc Sci Med. 2014;102:146-56. https://doi.org/10.1016/j.socsc imed.2013.11.004.

44. McMichael C. Climate Change and Migration: Food Insecurity as a Driver and Outcome of Climate Change-Related Migration. Environmental Deterioration and Human Health: Natural and Anthropogenic Determinants; 2013. p. 291-313.

45. Afifi T, Liwenga E, Kwezi L. Rainfall-induced crop failure, food insecurity and out-migration in Same-Kilimanjaro Tanzania. Clim Dev. 2014;6(1):53-60. https://doi.org/10.1080/17565 529.2013.826128.

46. De Vogli R, Birbeck GL. Potential impact of adjustment policies on vulnerability of women and children to HIV/AIDS in subSaharan Africa. J Health Popul Nutr. 2005;23(2):105-20.

47. Weiser SD, Tsai AC, Gupta R, et al. Food insecurity is associated with morbidity and patterns of healthcare utilization among HIV-infected individuals in a resource-poor setting. AIDS. 2012;26(1):67-75. https://doi.org/10.1097/QAD.0b013e3283 $4 \mathrm{cad} 37$.

48. Young S, Wheeler AC, McCoy SI, Weiser SD. A review of the role of food insecurity in adherence to care and treatment among adult and pediatric populations living with HIV and AIDS. AIDS Behav. 2014;18(5):505-15.

49. Franke MF, Murray MB, Munoz M, et al. Food insufficiency is a risk factor for suboptimal antiretroviral therapy adherence among HIV-infected adults in urban Peru. AIDS Behav. 2011;15(7):1483-9. https://doi.org/10.1007/s10461-010-9789-6.

50. Weiser SD, Palar K, Frongillo EA, et al. Longitudinal assessment of associations between food insecurity, antiretroviral adherence and HIV treatment outcomes in rural Uganda. AIDS. 2014;28(1):115-20. https://doi.org/10.1097/01.aids.0000433238 .93986 .35 .

51. Evans DL, Ten Have TR, Douglas SD, et al. Association of depression with viral load, CD8 T lymphocytes, and natural killer cells in women with HIV infection. Am J Psychiatry. 2002;159(10):1752-9.

52. Palar K, Kushel M, Frongillo EA, et al. Food insecurity is longitudinally associated with depressive symptoms among homeless and marginally-housed individuals living with HIV. AIDS Behav. 2014. https://doi.org/10.1007/s10461-014-0922-9.

53. Kalichman SC, Cherry C, Amaral C, et al. Health and treatment implications of food insufficiency among people living with HIV/ AIDS, Atlanta, Georgia. J Urban Health. 2010;87(4):631-41. https://doi.org/10.1007/s11524-010-9446-4.

54. Van der Sande MA, van der Loeff MFS, Aveika AA, et al. Body mass index at time of HIV diagnosis: a strong and independent predictor of survival. JAIDS J Acquir Immune Defic Syndr. 2004;37(2):1288-94.

55. Tang AM, Forrester J, Spiegelman D, Knox TA, Tchetgen E, Gorbach SL. Weight loss and survival in HIV-positive patients in the era of highly active antiretroviral therapy. J Acquir Immune Defic Syndr (1999). 2002;31(2):230-6.

56. Guenter P, Muurahainen N, Simons G, et al. Relationships among nutritional status, disease progression, and survival in HIV infection. J Acquir Immune Defic Syndr. 1993;6(10):1130-8.

57. Coutsoudis A, Bobat R, Coovadia HM, Kuhn L, Tsai W-y, Stein ZA. The effects of vitamin A supplementation on the morbidity of children born to HIV-infected women. American Journal of Public Health. 1995;85(8_Pt_1):1076-1081.

58. Macallan DC, Noble C, Baldwin C, et al. Energy expenditure and wasting in human immunodeficiency virus infection. $\mathrm{N}$ Engl $\mathrm{J}$ Med. 1995;333(2):83-8.

59. Gustavson L, Lam W, Bertz R, et al. Assessment of the bioequivalence and food effects for liquid and soft gelatin capsule co-formulations of ABT-378/ritonavir (ABT-378/r) in healthy subjects. 2000;17-20.

60. Ebi KL. Adaptation costs for climate change-related cases of diarrhoeal disease, malnutrition, and malaria in 2030. Global Health. 2008;4:9. https://doi.org/10.1186/1744-8603-4-9.

61. Park BJ, Sigel K, Vaz V, et al. An epidemic of coccidioidomycosis in Arizona associated with climatic changes, 1998-2001. J Infect Dis. 2005;191(11):1981-7.

62. Erickson RA, Hayhoe K, Presley SM, Allen LJS, Long KR, Cox SB. Potential impacts of climate change on the ecology of dengue and its mosquito vector the Asian tiger mosquito (Aedes albopictus). Environ Res Lett. 2012;7(3):034003. https://doi. org/10.1088/1748-9326/7/3/034003.

63. Patz JA, Olson SH. Malaria risk and temperature: Influences from global climate change and local land use practices. Proc Natl Acad Sci. 2006;103(15):5635-6.

64. Parham PE, Michael E. Modeling the effects of weather and climate change on malaria transmission. Environ Health Perspect. 2010;118(5):620-6. https://doi.org/10.1289/ehp.0901256.

65. Feria-Arroyo TP, Castro-Arellano I, Gordillo-Perez G, et al. Implications of climate change on the distribution of the tick vector Ixodes scapularis and risk for Lyme disease in the 
Texas-Mexico transboundary region. Parasites and Vectors. 2014;7(1):199. https://doi.org/10.1186/1756-3305-7-199.

66. Mason JB, Chotard S, Bailes A, Mebrahtu S, Hailey P. Impact of drought and HIV on child nutrition in Eastern and Southern Africa. Food Nutr Bull. 2010;31(3 Suppl):S209-218.

67. Abu-Raddad LJ, Patnaik P, Kublin JG. Dual infection with HIV and malaria fuels the spread of both diseases in sub-Saharan Africa. Science. 2006;314(5805):1603-6.

68. Patz JA, Reisen WK. Immunology, climate change and vectorborne diseases. Trends Immunol. 2001;4:171-2.

69. Ter Kuile FO, Parise ME, Verhoeff FH, et al. The burden of coinfection with human immunodeficiency virus type 1 and malaria in pregnant women in sub-saharan Africa. Am J Tropic Med Hygiene. 2004;71(2_Suppl):41-54.

70. Von Seidlein L, Wang XY, Macuamule A, et al. Is HIV infection associated with an increased risk for cholera? Findings from a case-control study in Mozambique. Tropic Med Int Health. 2008;13(5):683-8.

71. Githeko AK, Lindsay SW, Confalonieri UE, Patz JA. Climate change and vector-borne diseases: a regional analysis. Bull World Health Organ. 2000;78(9):1136-47.

72. Brisbois BW, Ali SH. Climate change, vector-borne disease and interdisciplinary research: social science perspectives on an environment and health controversy. EcoHealth. 2010;7(4):425-38.

73. Semenza JC, Suk JE. Vector-borne diseases and climate change: a European perspective. FEMS Microbiol Lett. 2018;365(2):fnx244.

74. Khasnis AA, Nettleman MD. Global warming and infectious disease. Arch Med Res. 2005;6:689-96.

75. Hoffman IF, Jere CS, Taylor TE, et al. The effect of Plasmodium falciparum malaria on HIV-1 RNA blood plasma concentration. Aids. 1999;13(4):487-94.

76. Epstein PR. Climate change and emerging infectious diseases. Microb Infect. 2001;3(9):747-54

77. Bai L, Morton LC, Liu Q. Climate change and mosquito-borne diseases in China: a review. Globaliz Health. 2013;9(1):10. https ://doi.org/10.1186/1744-8603-9-10.

78. Ready P. Leishmaniasis emergence and climate change. Revue Scientifique Et Technique-Office International Des Epizooties. 2014;27(2)

79. Franke CR, Ziller M, Staubach C, Latif M. Impact of El niño/ southern oscillation on visceral leishmaniasis, Brazil. Emerg Infect Dis. 2002;8(9):914.

80. Alvar J, Aparicio P, Aseffa A, et al. The relationship between leishmaniasis and AIDS: the second 10 years. Clin Microbiol Rev. 2008;21(2):334-59.

81. Mills JN, Gage KL, Khan AS. Potential influence of climate change on vector-borne and zoonotic diseases: a review and proposed research plan. Environ Health Perspect. 2010;118(11):1507-14.

82. Rocklöv J, Sjödin H. High population densities catalyse the spread of COVID-19. J Travel Med. 2020;27(3):taaa038.

83. Schwartz SA. America, COVID-19, Climate change, and migration. Explore (New York, Ny). 2020

84. Chamie J. International Migration amid a World in Crisis. J Migrat Human Secur. 2020;2331502420948796.

85. Chakraborty I, Maity P. COVID-19 outbreak: Migration, effects on society, global environment and prevention. Sci Total Environ 2020:138882.

86. Cooper T, Woodward B, Alom S, Harky A. Coronavirus disease 2019 (COVID-19) outcomes in HIV/AIDS patients: a systematic review. HIV Med. 2020.

87. Nyoni T, Okumu M. COVID-19-Compliant Strategies for Supporting Treatment Adherence Among People Living with HIV in Sub-Saharan Africa. AIDS and Behavior. 2020:1.
88. Jiang H, Zhou Y, Tang W. Maintaining HIV care during the COVID-19 pandemic. Lancet HIV. 2020;7(5):e308-9.

89. Alexander KA, Heaney AK, Shaman J. Hydrometeorology and flood pulse dynamics drive diarrheal disease outbreaks and increase vulnerability to climate change in surface-waterdependent populations: A retrospective analysis. PLoS Med. 2018;15(11):e1002688.

90. Cash BA, Rodo X, Emch M, Yunus MD, Faruque ASG, Pascual M. Cholera and shigellosis: Different epidemiology but similar responses to climate variability. PLoS ONE. 2014;9(9):A1306. https://doi.org/10.1371/journal.pone.0107223.

91. Hunter PR. Climate change and waterborne and vector-borne disease. J Appl Microbiol. 2003;37S-46S.

92. Lew EA, Poles MA, Dieterich DT. Diarrheal diseases associated with HIV infection. Gastroenterol Clin North Am. 1997;26(2):259-90.

93. Katabira ET. Epidemiology and management of diarrheal disease in HIV infected patients. Int J Infect Dis. 1999;3(3):164-7.

94. Chowdhury FR, Nur Z, Hassan N, von Seidlein L, Dunachie S. Pandemics, pathogenicity and changing molecular epidemiology of cholera in the era of global warming. Ann Clin Microbiol Antimicrob. 2017;16(1):1-6.

95. Lipp EK, Huq A, Colwell RR. Effects of global climate on infectious disease: the cholera model. Clin Microbiol Rev. 2002;15(4):757-70.

96. Rey J-L, Milleliri J-M, Scares J-L, et al. HIV seropositivity and cholera in refugee children from Rwanda. Aids. 1995;9(10):1203.

97. Mushayabasa S, Bhunu CP. Is HIV infection associated with an increased risk for cholera? Insights from a mathematical model. Biosystems. 2012;109(2):203-13.

98. Armstrong-James D, Meintjes G, Brown GD. A neglected epidemic: fungal infections in HIV/AIDS. Trends Microbiol. 2014;22(3):120-7.

99. Pakpour S, Li D-W, Klironomos J. Relationships of fungal spore concentrations in the air and meteorological factors. Fungal Ecol. $2015 ; 13: 130-4$.

100. Tong DQ, Wang JX, Gill TE, Lei H, Wang B. Intensified dust storm activity and Valley fever infection in the southwestern United States. Geophys Res Lett. 2017;44(9):4304-12.

101. Stansell J. Pulmonary fungal infections in HIV-infected persons. 1993;116-123.

102. MMWR. Coccidiomycosis - Arizona, 1990-1995. Morb Mortal Wkly Rep. 1996;45:1069-1073. http://hivinsite.ucsf.edu/InSit e-KB-ref.jsp?page $=\mathrm{kb}-05-02-04 \& \mathrm{rf}=5$

103. Shackleton SE, Shackleton CM. Linking poverty, HIV/AIDS and climate change to human and ecosystem vulnerability in southern Africa: Consequences for livelihoods and sustainable ecosystem management. Int J Sustain Dev World Ecol. 2012;19(3):275-86. https://doi.org/10.1080/13504509.2011.641039.

104. Biermann F, Boas I. Preparing for a warmer world: Towards a global governance system to protect climate refugees. Global Environ Politics. 2010;10(1):60-88.

105. Malcolm JR, Markham A, Neilson RP, Garaci M. Estimated migration rates under scenarios of global climate change. J Biogeogr. 2002;29(7):835-49.

106. Rahmstorf S. A new view on sea level rise. Nat Clim Change. 2010;1(1004):44-5.

107. McGranahan G, Balk D, Anderson B. The rising tide: assessing the risks of climate change and human settlements in low elevation coastal zones. Environ Urbaniz. 2007;19(1):17-37.

108. Rigaud KK, Jones B, Bergmann J, et al. Groundswell: Preparing for Internal Climate Migration. Washington, DC: World Bank; 2018.

109. Black R, Adger N, Arnell N, Dercon S, Geddes A, Thomas D. Migration and global environmental change: future challenges and opportunities. 2011. 
110. Myers N. Environmental refugees: a growing phenomenon of the 21st century. Philosoph Transact Royal Soc London B: Biol Sci. 2002;357(1420):609-13.

111. Brzoska M, Fröhlich C. Climate change, migration and violent conflict: vulnerabilities, pathways and adaptation strategies. Migrat Dev. 2016;5(2):190-210.

112. Brockerhoff M, Biddlecom AE. Migration, sexual behavior and the risk of HIV in Kenya. Int Migrat Rev. 1999;833-856.

113. Lurie MN, Williams BG, Zuma K, et al. The impact of migration on HIV-1 transmission in South Africa: a study of migrant and nonmigrant men and their partners. Sex Transm Dis. 2003;30(2):149-56.

114. Brummer D. Labour migration and HIV/AIDS in southern Africa. Int Organiz Migrat Region Office Southern Africa. 2002.

115. Docquier F, Vasilakis C, Tamfutu MD. International migration and the propagation of HIV in sub-Saharan Africa. J Health Econ. 2014;35(1):20-33. https://doi.org/10.1016/j.jheal eco.2014.01.004

116. Sakschewski B, Von Bloh W, Huber V, Müller C, Bondeau A. Feeding 10 billion people under climate change: How large is the production gap of current agricultural systems? Ecol Model. 2014;288:103-11.

117. City BL, Assessment E. Urbanization and health. Bull World Health Organ. 2010;88(4):245-6.

118. Ritchie H, Roser M. Urbanization. Our world in Data. 2018.

119. Miles EL, Elsner MM, Littell JS, Binder LW, Lettenmaier DP. Assessing regional impacts and adaptation strategies for climate change: the washington climate change impacts assessment. Clim Change. 2010;102(1-2):9-27. https://doi.org/10.1007/s1058 4-010-9853-2.

120. Henderson JV, Turner MA. Urbanization in the developing world: too early or too slow? 2020;0898-2937.

121. Lane K, Charles-Guzman K, Wheeler K, Abid Z, Graber N, Matte T. Health effects of coastal storms and flooding in urban areas: a review and vulnerability assessment. J Environ Public Health. 2013;2013:913064. https://doi.org/10.1155/2013/91306 4.

122. Van Minh H, Tuan Anh T, Rocklov J, et al. Primary healthcare system capacities for responding to storm and flood-related health problems: a case study from a rural district in central Vietnam. Glob Health Action. 2014;23007.

123. Anthonj C, Nkongolo OT, Schmitz P, Hango JN, Kistemann T. The impact of flooding on people living with HIV: a case study from the Ohangwena Region, Namibia. Global Health Action. 2015;8(1):26441. https://doi.org/10.3402/gha.v8.26441.
124. Chinowsky P, Schweikert A, Strzepek N, Manahan K, Strzepek K. Adaptation advantage to climate change impacts on road infrastructure in Africa through 2100. WIDER Working Paper. 2011.

125. Consulting S. Climate Change Impacts on Transportation Infrastructure. Report Prepared for U.S. Environmental Protection Agency, Stratus Consulting, Boulder, CO2010.

126. Economics I. Costing climate impacts and adaptation: A Canadian study on public infrastructure. Ontario, Canada: National Round Table on the Environment and the Economy Ottawa; 2010 .

127. Kaberuka D. Kaberuka: Africa needs usd 40 billion/year in climate aid. African Dev Bank Group. 2009;12(02):2009.

128. Chinowsky PS, Schweikert AE, Strzepek NL, Strzepek K. Infrastructure and climate change: a study of impacts and adaptations in Malawi, Mozambique, and Zambia. Clim Change. 2015;130(1):49-62.

129. Scientists UoC. Each Country's Share of CO2 Emissions. https ://www.ucsusa.org/global-warming/science-and-impacts/science/ each-countrys-share-of-co2.html2018.

130. WB. Preparing, Procuring, and Implementing Climate-Smart PPPs. https://ppp.worldbank.org/public-private-partnership/ climate-smart-clean-technology-ppps/preparing-procuring-andimplementing-climate-smart-ppps (2020). Accessed 6 Sep 2020.

131. McMichael A, Butler C, Weaver H. Climate change and AIDS: a joint working paper. UNEP and UNAIDS. 2008.

132. Sanchez PA, Denning GL, Nziguheba G. The African green revolution moves forward. Food Secur. 2009;1(1):37-44.

133. Smit B, Skinner MW. Adaptation options in agriculture to climate change: a typology. Mitig Adapt Strat Glob Change. 2002;7(1):85-114.

134. Nevill C, Some E, Mung'Ala V, et al. Insecticide-treated bednets reduce mortality and severe morbidity from malaria among children on the Kenyan coast. Tropical Med Int Health. 1996;1(2):139-46.

135. Lengeler $\mathrm{C}$. Insecticide-treated bed nets and curtains for preventing malaria. Cochrane Database of Syst Rev. 2004;(2)

136. Chazan M, Brklacich M, Whiteside A. Rethinking the conceptual terrain of AIDS scholarship: lessons from comparing 27 years of AIDS and climate change research. Global and Health. 2009. https://doi.org/10.1186/1744-8603-5-12.

Publisher's Note Springer Nature remains neutral with regard to jurisdictional claims in published maps and institutional affiliations. 